\title{
Erratum to: Impact of Water Quality Parameters on the Clogging of Vertical-Flow Constructed Wetlands Treating Urban Wastewater
}

\begin{abstract}
Abdulkadir Sani • Miklas Scholz •
Akintunde Babatunde • Yu Wang
\end{abstract}

Published online: 24 August 2013

(C) Springer Science+Business Media Dordrecht 2013

\section{Erratum to: Water Air Soil Pollut DOI 10.1007/s11270-013-1488-2}

The sentence "The application of Darcy's law only provides an approximation of the media hydraulic conductivity as it cannot take into account the varying thickness of the water table resulting from the porous media flow energy balance (i.e., $A_{w}$ varies between the upstream and downstream point." in section 3.5 is mistakenly missing the closing words and bracket, and thus the proper citations.

The corrected sentence should read "In general, the application of Darcy's law only provides an approximation of the media hydraulic conductivity as it cannot take into account the varying thickness of the water table resulting from the porous media flow energy balance (i.e., $A_{w}$ varies between the upstream and downstream point (Bear 1979) for horizontal-flow systems as discussed by Nivala et al. (2012))."

The missing references are:

Bear, J. (1979). Hydraulics of groundwater. London: McGraw-Hill.

Nivala, J., Knowles P., Dotro G., García J., \& Wallace S. (2012). Clogging in subsurface-flow treatment wetlands: Measurement, modeling and management. Water Research, 46, 1625-1640.

The authors apologize for this error.

The online version of the original article can be found at http:// dx.doi.org/10.1007/s11270-013-1488-2.

A. Sani $\cdot$ M. Scholz $(\bowtie) \cdot$ Y. Wang

Civil Engineering Research Centre, School of Computing,

Science and Engineering, The University of Salford, Newton Building, Salford M5 4WT, England, UK

e-mail: m.scholz@salford.ac.uk

\section{A. Babatunde}

Institute of Environment and Sustainability,

Cardiff School of Engineering, Cardiff University,

Queen's Buildings, The Parade,

Cardiff CF24 3AA, Wales, UK 